\title{
Value of Neo-Puff as a tool for Sustained Lung Inflation in Preterm babies
}

O.A.ElfIki, T.M.khatab, E.H.Assar and D.A.Madian

Pediatrics Dept., Faculty of Medicine, Benha Univ., Benha, Egypt

E-Mail: D.A.Madian@gmail.com

\begin{abstract}
Preterm labor is an obstetrics emergency and a threat to population health. $75 \%$ of infant mortality is related to preterm labor, to detect and predict efficacy of Neo-puff as a tool for sustained lung inflation on preterm, 100 preterm children were included in this study, The patients were divided in to 2 groups: Group A: SLI inflation and Group B: assessed as usually. Then the groups were compared regarding their outcome and their need of respiratory assessment. there was a statistical difference between groups regarding need to mechanical ventilator, as $34 \%$ of group A and $54 \%$ in group $\mathrm{B}(\mathrm{p}=0.035)$, there was a statistical difference between groups regarding the time of use of mechanical ventilator, the use of mechanical ventilator in the $1 \mathrm{st}$ day was higher $(46 \%)$ in group B, compared to only $14 \%$ of group A, $\mathrm{p}=0.004$, there was no statistical difference between groups regarding occurrence of BPD, hospitalization or mortality rate. Sustained lung inflation is easier to perform even with a single operator; it reduces the necessity of mechanical ventilator in the first 72 hours without statistically evident adverse effects. However, did not decrease the need for respiratory support, occurrence of BPD, hospitalization or mortality rate.
\end{abstract}

Keywords: Preterm, RDS, Neo-puff, Sustained lung inflation.

\section{Introduction}

The World Health Organisation (WHO) defines preterm birth as any birth before 37 completed weeks of gestation, or fewer than 259 days since the first day of the woman's last menstrual period (LMP) [1], Preterm labor is an obstetrics emergency and a threat to population health. $75 \%$ of infant mortality is related to preterm labor. [2]

Although the mortality rate for preterm infants and the gestational age-specific mortality rate have dramatically improved over the last 3 to 4 decades, infants born preterm remain vulnerable to many complications, including respiratory distress syndrome, chronic lung disease, injury of the intestines, a compromised immune system, cardiovascular disorders, hearing and vision problems, and neurological insult [3].

Respiratory distress is one of the most common reasons an infant is admitted to the neonatal intensive care unit. Fifteen percent of term infants and $29 \%$ of late preterm infants admitted to the neonatal intensive care unit develop significant respiratory morbidity; this is even higher for infants born before 34 weeks' gestation [4], Because fetal lung maturation occurs late in gestation. Anomalies in the process of fetal lung fluid reabsorption and surfactant deficiency are the main factors inVol..ved in respiratory disorders of preterm infants [5].

However, predicting which infants will become symptomatic is not always possible before birth. Regardless of the cause, if not recognized and managed quickly, respiratory distress can escalate to respiratory failure and cardiopulmonary arrest. Therefore, it is imperative that any health care practitioner caring for newborn infants can readily recognize the signs and symptoms of respiratory distress, differentiate various causes, and initiate management strategies to prevent significant complications or death. [4]

Recent studies have investigated the effect that the sustained lung inflation (SLI) procedure has in preterm infants on avoiding the need for MV. This strategy would permit lung recruitment immediately after birth through delivery of brief peak pressure to the infant airways via a nasopharyngeal tube or mask, allowing preterm infants to achieve Functional Residual Capacity (FRC). The application of PEEP helps to avoid lung collapse at the end of the expiration. SLI and PEEP seem to have an additive effect on adequate FRC formation by permitting optimal gas exchange, improving lung mechanics, and reducing the need for respiratory support. [6]

An international consensus statement recommends that positive pressure ventilation (PPV) can be provided with a face mask and selfinflating bag (SIB) or a flow-inflating bag (FIB) or a T-piece resuscitator (TPR). It's recommended that all three devices be used with an oxygen blender, if possible, to enable the user to adjust the oxygen percentage. [7]

Of the three devices, the infant T-piece resuscitator (Neo-puff) provides the most consistent PIP and PEEP. As with the first two devices, some models attach directly to a standard flow meter. The infant T-piece resuscitator is supported by the Neonatal Resuscitation Program (NPR) and has been shown in many studies to be an effective, safe method of ventilation even in inexperienced hands. [8], [9]

As for the clinician, there are no fatigue issues with extended use that may occur with the other devices. An article in Resuscitation in 2010 stated: "Use of infant T-piece devices guarantees reliable and constant $\mathrm{Vt}$ and PIP provision, irrespective of individual, operator dependent, and variables." [10] 
The study aims to detect and predict efficacy of Neo-puff as a tool for sustained lung inflation on preterm.

\section{Patients and methods}

This study was carry out on preterm infant delivered at Benha University Hospitals from April 2019 to October 2019. It comprised preterm of both sexes after obtaining an informed consent from caregiver.

Inclusion criteria:Preterm aged 28-35 weeks of gestation, Both sexes (Males and females).

\subsection{Exclusion criteria}

- The presence of major congenital malformations: (ie, congenital heart, cerebral, lung, abdominal malformations).

- Fetal hydrops

- Lack of parental consent.

Approval of the study protocol by an Ethical Scientific Committee of Benha University was obtained and informed consent was obtained from the parents before enrollment in the study.

Study suggest that giving newly born preterm infants sustained lung inflation (SLI) may decrease their need for mechanical ventilation (MV) and improve their respiratory outcomes.

We randomly assigned infants born at 28 weeks to 35 weeks to receive sustained lung inflation $(25 \mathrm{~cm} \mathrm{H} 2 \mathrm{O}$ for 15 seconds followed by PEEP $6 \mathrm{~cm} \mathrm{H2o}$ ) by Neo-puff in the delivery room.

Infants were assigned immediately after birth before the first breath to receive either SLI maneuvers and nCPAP or nCPAP alone in a $1: 1$ ratio in permuted blocks of variable size.

The study was not blinded, and the staff performing the study also cared for the infants later on. The decision to start MV was made by clinicians other than the investigators inVol..ved in the study according to specific guidelines, and researchers assessing study end points were blinded to the nature of the study treatments.

Infants in the SLI group underwent the following approach: after oropharyngeal and nasal suctioning, a pressure-controlled $(25 \mathrm{~cm} \mathrm{H}$ 2 O) inflation was sustained for 15 seconds, followed by the delivery of $6 \mathrm{~cm} \mathrm{H} 2 \mathrm{O}$ CPAP, using a neonatal mask and a $\mathrm{T}$-piece ventilator.

- A peak pressure of $25 \mathrm{~cm} \mathrm{H} 20$ was chosen because this level had been shown to be effective and safe in previous studies [6], [11]

- An inflation duration of 15 seconds was used because it had been well tolerated and followed by a greater FRC in previous clinical and experimental studies. [6], [12]

- The flow rate was set at 8 to $10 \mathrm{~L} / \mathrm{min}$ before resuscitation and was not changed during resuscitation. Patients were observed for the next 6 to 10 seconds to evaluate their cardiorespiratory function. If respiratory failure persisted (ie, apnea, gasping) and/or the heart rate was . 60 and , 100 beats/min despite CPAP, the SLI maneuver (again $25 \mathrm{~cm} \mathrm{H} 2 \mathrm{O}$ for 15 seconds) was repeated.

- If the heart rate remained 60 and, 100 beats $/ \mathrm{min}$ after the second SLI maneuver, the infant was resuscitated following the guidelines of the American Academy of Pediatrics. [13]

- Infants in the other group were treated with nCPAP at $5 \mathrm{~cm} \mathrm{H} 2 \mathrm{O}$ and were assisted according to the guidelines of the American Academy of Pediatrics.

- Infants in both groups who were not intubated in the delivery room were transferred to the NICU on nCPAP at $5 \mathrm{~cm} \mathrm{H} 2 \mathrm{O}$ with a fraction of inspired oxygen (FIO2 ) of 0.21 to 0.40 (in agreement with local protocols).

A standardized data sheet was utilized to record perinatal history, clinical examination and investigations that are performed.

The patients were divided in to 2 groups: Group A: SLI inflation and Group B: assessed as usually.

\subsection{Statistical analysis}

The data were coded, entered and processed on computer using SPSS (version 24). The results were represented in tabular and diagrammatic forms then interpreted. Mean, standard deviation, range, frequency, and percentage were use as descriptive statistics. The following test was done: Chi-Square test $\mathrm{X}^{2}$ was used to test the association variables for categorical data. Student's t-test was used to assess the statistical significance of the difference between two population means in a study inVol..ving independent samples, with normal distribution

\section{Results}

Patients were divided into two groups: Group A: SLI group and Group B: including patients assessed by standard methods, 50 patients in each group. In group A males was $24(48 \%)$, while in group B males were 21(42\%). there was no statistical difference between groups regarding their mode of delivery. Cesarean section was done in $82 \%$ of Group A and $84 \%$ in Group B. and there was no statistical difference between groups regarding singleton, Twins rate was $20 \%$ in group A and $24 \%$ in group B other babies were single, no triplets were detected in this study. regarding maternal risk factors, $46 \%$ of group A mothers had PROM, compared to only $24 \%$ in group B, $18 \%$ of group A and $20 \%$ of group B mothers had chorioamnionitis, $14 \%$ of group A and $20 \%$ of group B mothers had hypertensive disorders, $8 \%$ of group A and 14\% of group B mothers had UTI, $72 \%$ of group A and $76 \%$ of group B had a history of antenatal steroids and 
$4 \%$ of both groups mothers had DM. But there was no statistical difference between groups

regarding those risk factors. Table (1).

Table(1) Comparison between groups regarding fetal and maternal risk factors

\begin{tabular}{|c|c|c|c|c|c|}
\hline \multicolumn{2}{|l|}{ Variable } & $\begin{array}{c}\text { Group A } \\
\mathbf{N}=\mathbf{5 0}\end{array}$ & $\begin{array}{c}\text { Group B } \\
\mathbf{N}=50\end{array}$ & Test & p-value \\
\hline \multirow[t]{2}{*}{ Mode of delivery } & $\mathrm{CS}$ & $41(82 \%)$ & $42(84 \%)$ & $\chi^{2}=0.071$ & 0.790 \\
\hline & NVD & $9(18 \%)$ & $8(16 \%)$ & & \\
\hline \multirow[t]{2}{*}{ Singleton } & Single & $40(80 \%)$ & $38(76 \%)$ & $\chi^{2}=0.056$ & 0.812 \\
\hline & Twins & $5(20 \%)$ & $6(24 \%)$ & & \\
\hline \multirow[t]{2}{*}{ PROM } & $\mathrm{N}$ & 23 & 12 & & \\
\hline & $\%$ & $46 \%$ & $24 \%$ & & \\
\hline \multirow[t]{2}{*}{ Chorio-amnionitis } & $\mathrm{N}$ & 9 & 10 & & \\
\hline & $\%$ & $18 \%$ & $20 \%$ & $\chi 2=6.324$ & 0.176 \\
\hline \multirow[t]{2}{*}{ Hypertensive disorders } & $\mathrm{N}$ & 7 & 10 & & \\
\hline & $\%$ & $6 \%$ & $20 \%$ & & \\
\hline \multirow[t]{2}{*}{ UTI } & $\mathrm{N}$ & 4 & 7 & & \\
\hline & $\%$ & $8 \%$ & $14 \%$ & & \\
\hline \multirow[t]{2}{*}{ Diabetes mellitus } & $\mathrm{N}$ & 2 & 2 & & \\
\hline & $\%$ & $4 \%$ & $4 \%$ & & \\
\hline \multirow[t]{2}{*}{ Antenatal steroids (Full dose) } & $\mathrm{N}$ & 36 & 38 & & \\
\hline & $\%$ & $72 \%$ & $76 \%$ & & \\
\hline
\end{tabular}

\section{$\chi^{2}:$ Chi-square test}

In this study, there was a statistical difference between groups regarding need to mechanical ventilator, as $34 \%$ of group A and $54 \%$ in group B $(p=0.035)$, there was a statistical difference between groups regarding the time of use of mechanical ventilator, the use of mechanical ventilator in the 1 st day was higher $(46 \%)$ in group B, compared to only $14 \%$ of group A, $\mathrm{p}=0.004$; odds ratio $0.439 ; 95 \% \mathrm{CI}(0.196-0.984)$. $34 \%$ of group A required high $\mathrm{O} 2$ support compared to $46 \%$ of group B. However, there was no statistical difference between them. Also there was no statistical difference between them regarding the duration of high $\mathrm{O} 2$ support or the duration of CPAP, table (2) and fig (1).

Table (2) Comparison between groups regarding their need to survanta, high O2 support and mechanical ventilator.

\begin{tabular}{lccccc}
\hline Variables & & $\begin{array}{c}\text { Group A } \\
\mathbf{N = 5 0}\end{array}$ & $\begin{array}{c}\text { Group B } \\
\mathbf{N}=\mathbf{5 0}\end{array}$ & Test & p-value \\
\hline Need of Survanta & $\mathrm{N}$ & 9 & 11 & $\chi 2=0.250$ & 0.803 \\
& $\%$ & $18 \%$ & $22 \%$ & & \\
Need high O2 & $\mathrm{N}$ & 17 & 23 & $\chi 2=2.71$ & 0.210 \\
support & $\%$ & $34 \%$ & $46 \%$ & & \\
Need of mechanical & $\mathrm{N}$ & 17 & 27 & $\chi 2=4.058$ & $0.035^{*}$ \\
ventilator & $\%$ & $34 \%$ & $54 \%$ & & \\
Duration of high & Mean $\pm \mathrm{SD}$ & $6.94 \pm 3.5$ & $6.72 \pm 3.4$ & $\mathrm{t}=0.315$ & 0.753 \\
O2 support (days) & Range & $2-16$ & $1-15$ & & \\
Duration of CPAP & Mean $\pm \mathrm{SD}$ & $3.46 \pm 2.1$ & $3.1 \pm 2.25$ & $\mathrm{t}=0.821$ & 0.414 \\
(days) & Range & $1-8$ & $1-10$ & & \\
$\begin{array}{l}\text { Duration of } \\
\text { mechanical vent. }\end{array}$ & Mean $\pm \mathrm{SD}$ & $2.46 \pm 2.5$ & $5.2 \pm 2.15$ & $\mathrm{t}=1.754$ & 0.071 \\
(days) & Range & $1-5$ & $1-9$ & & \\
\hline
\end{tabular}

\section{$\chi^{2}:$ Chi-square test}

In this study, there was no statistical difference betwwen group regarding occurring of complications, also there was no statistical difference between groups regarding mean length of stay in hospital, was $14.54 \pm 10.2$ in group A and $19.92 \pm 12.6$ in group $\mathrm{B}, \mathrm{p}=0.065$. Also regarding mortality rate $18 \%$ in SLI group and $22 \%$ in controls, $\mathrm{p}=0.402$ Table (3). 


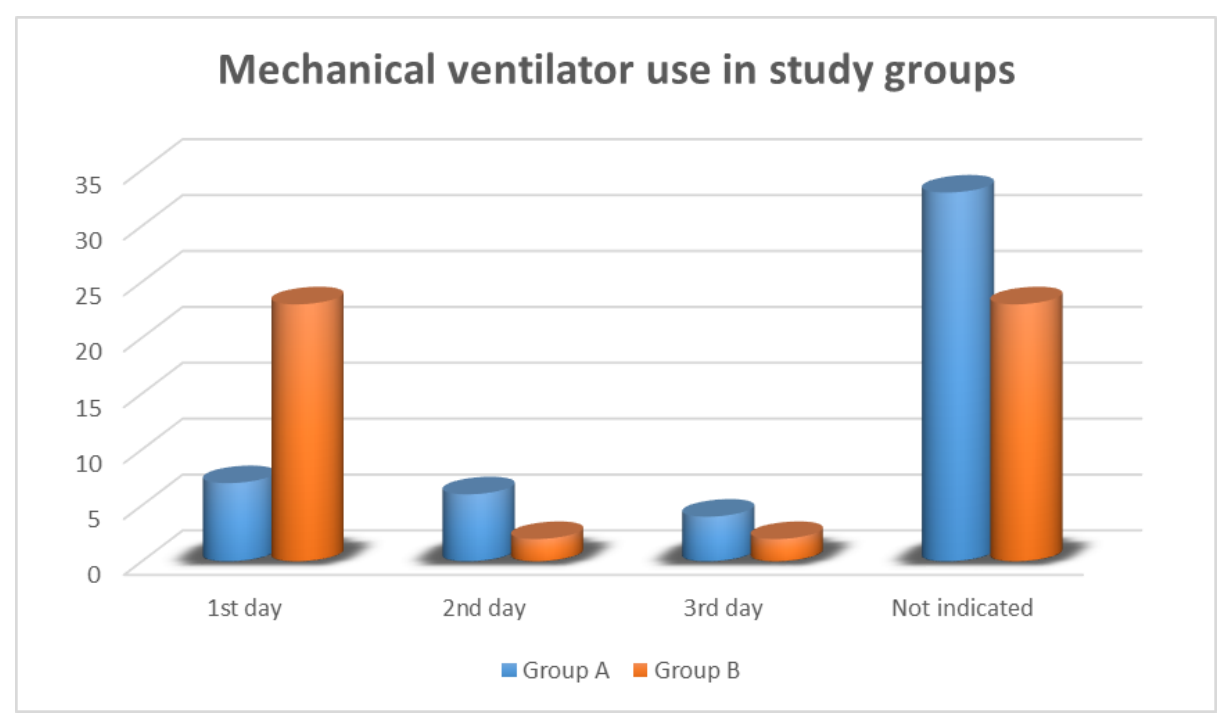

Fig (1) Comparison between groups regarding use of mechanical ventilator

Table (3) Comparison between groups regarding occurrence of complications

\begin{tabular}{|c|c|c|c|c|c|}
\hline Variables & & $\begin{array}{c}\text { Group A } \\
\mathbf{N}=\mathbf{5 0}\end{array}$ & $\begin{array}{c}\text { Group B } \\
\mathbf{N}=\mathbf{5 0}\end{array}$ & Test & p-value \\
\hline \multirow[t]{2}{*}{ BPD } & $\mathrm{N}$ & 1 & 2 & $\chi 2=0.344$ & 0.500 \\
\hline & $\%$ & $2 \%$ & $4 \%$ & & \\
\hline \multirow[t]{2}{*}{ pneumothorax } & $\mathrm{N}$ & 4 & 2 & $\chi 2=0.709$ & 0.339 \\
\hline & $\%$ & $8 \%$ & $4 \%$ & & \\
\hline \multirow[t]{2}{*}{ Sepsis } & $\mathrm{N}$ & 17 & 14 & $\chi 2=421$ & 0.333 \\
\hline & $\%$ & $34 \%$ & $28 \%$ & & \\
\hline \multirow[t]{2}{*}{ NEC } & $\mathrm{N}$ & 1 & 1 & - & - \\
\hline & $\%$ & $2 \%$ & $2 \%$ & & \\
\hline \multirow[t]{2}{*}{ IVH } & $\mathrm{N}$ & 6 & 3 & $\chi 2=1.099$ & 0.243 \\
\hline & $\%$ & $12 \%$ & $6 \%$ & & \\
\hline \multirow[t]{2}{*}{ ROP } & $\mathrm{N}$ & 2 & 3 & $\chi 2=0.543$ & 0.357 \\
\hline & $\%$ & $4 \%$ & $6 \%$ & & \\
\hline \multirow[t]{2}{*}{ Mortality } & $\mathrm{N}$ & 9 & 11 & $\chi 2=0.250$ & 0.402 \\
\hline & $\%$ & $18 \%$ & $22 \%$ & & \\
\hline \multirow{2}{*}{$\begin{array}{l}\text { Length of hospital } \\
\text { stay (days) }\end{array}$} & Mean \pm SD & $14.54 \pm 10.2$ & $19.92 \pm 12.6$ & $\mathrm{t}=1.342$ & 0.065 \\
\hline & Range & 3-38 & $2-45$ & & \\
\hline
\end{tabular}

$\chi^{2}$ : Chi-square test; BPD: bronchopulmonary dysplasia; NEC: necrotizing enterocolities; IVH: intraventricular hemorrhage; ROP: retinopathy of prematurity.

\section{Discussion}

In this study, there was a female predominance in both groups, this came in agree with [14], who observed that the majority of the 68 preterm in their study was female $(52 \%)$, in a study on growth curves and dietary profile of preterm newborns with appropriate weight for gestational age during hospital stay. [15] had a similar observation.

In contrast to [16] on a study on gestational age-specific sex difference in mortality and morbidities of preterm infants, A total of 2228 preterms (males, $\mathrm{n}=1151,51.7 \%$; females, $\mathrm{n}=1077,48.3 \%$ ). Also so many old and recent studies observed the male predominance, moreover observed that preterm male infants appear to have consistently worse outcomes compared to females. [17]-[20].

In this study, Mean gestational age was $(32.82 \pm 1.6)$ weeks in group A and $(33.1 \pm 1.7)$ weeks in group B. Mean head circumference mean was $(30.9 \pm 1.7) \mathrm{cm}$ in group $\mathrm{A}$ and $(31.3 \pm 1.6) \mathrm{cm}$ in group B. Mean length mean was $(44.2 \pm 3.8) \mathrm{cm}$ in group $\mathrm{A}$ and $(45 \pm 3.5) \mathrm{cm}$ in group B. Mean weight mean was $(1.6 \pm 0.3) \mathrm{kg}$ in group A and $(1.7 \pm 0.4) \mathrm{kg}$ in Group B. There was no statistical difference between groups regarding 
their gestational age, head circumference, length or weight at birth.

Similarly was observed in [15] study, on his study about the impact of SLI on brain, The 40 included preterm infants had a mean gestational age(GA) of 32 weeks one day ( \pm 2 days), birth weight of $1707( \pm 470)$ g., and HC of $29.7( \pm 2)$ $\mathrm{cm}$., with no significant differences between groups.

In [5] study, mean GA was $35 \pm 0.8$ in SLI groups and $35.2 \pm 0.8$ in controls and mean weight was $2345 \pm 397 \mathrm{~g}$ in SLI group and 2346 \pm 359 in controls.

In [6], the design of the study to include babies from 25 to 28 week and 6 days, This age group was chosen because it is at high risk of RDS. In their study the mean birth weight was $893 \pm 241$ g. in SLI group and $894 \pm 247$ in controls.

In this study, there was no statistical difference between groups regarding their mode of delivery. Cesarean section was done in $82 \%$ of Group A and 84\% in Group B.

In [5] study, More than $90 \%$ of infants were born by cesarean section in both groups; also in [6] $81 \%$ of preterm births were born by cesarean section in both groups. While in [21] study, the babies born by CS ranged from $39 \%$ to $50 \%$ between groups.

In this study, there was no statistical difference between groups regarding singleton, Twins rate was $20 \%$ in group A and $24 \%$ in group $\mathrm{B}$ other babies were single, no triplets were detected in this study.

In [5] study, Twins accounted for over $50 \%$ of the study population. And in [6] accounts $32 \%$ and $33 \%$ in SLI and control groups, respectively.

Twin pregnancies are associated with a threefold greater perinatal mortality than singleton pregnancies. Prematurity is a main contributor, with $50 \%$ of twin pregnancies delivering before 37 weeks and $10 \%$ delivering before 32 weeks of gestation. [22]

In this study, there was no statistical difference between groups regarding their Apgar at the 1 st and 5 th minutes after birth. In the $1^{\text {st }}$ minute mean Apgar score in group A and group B was $5.2 \pm 1.3$ and $5.5 \pm 1.4$ respectively, and in the $5^{\text {th }}$ minute was $8.6 \pm 1.2$ and $8.1 \pm 1.1$ respectively, however the relative increase of Apgar score after 5 minutes in group A than group B, there was no statistical difference.

In [15] study, median Apgar score in 1st min. was 8 (5-9) in SLI group and 8 (6-9) in controls and was 9 (8-9) in SLI and controls with no statistical differences between groups.

In contrast to [23], on their study about sustained versus intermittent lung inflation for resuscitation of preterm infants, SLI had a higher 5-min-Apgar score (median 8 versus 7; $\mathrm{p}=0.018$ ). also [24] observed that Apgar score at 1 min wasn't significant; $\mathrm{p}=0.07$ then became significant at $5 \mathrm{~min} ; \mathrm{p}=0.04$.

In this study, regarding maternal risk factors, $46 \%$ of group A mothers had PROM, compared to only $24 \%$ in group B, $18 \%$ of group A and $20 \%$ of group B mothers had chorioamnionitis, $14 \%$ of group A and $20 \%$ of group B mothers had hypertensive disorders, $8 \%$ of group $\mathrm{A}$ and $14 \%$ of group B mothers had UTI, $72 \%$ of group A and $76 \%$ of group B had a history of antenatal steroids and $4 \%$ of both groups mothers had DM. But there was no statistical difference between groups regarding those risk factors.

[24] had a similar observations in their study on sustained lung inflation at birth via short binasal prong in very low birth weight preterm infants, as mothers of $17.7 \%$ of SLI group had PROM compared to $14.7 \%$ of controls; $\mathrm{p}=0.55$, $20.4 \%$ of mothers of SLI group had preeclampsia compared to $26.5 \%$ of controls; $p=0.33$ and $10.6 \%$ of SLI group mothers had chorioamionitis compared to $10.8 \%$ of comtrols; $\mathrm{p}=0.96$.

Also in [6] study, $26 \%$ of SLI group mothers had PROM compared to $27 \%$ of controls, $24 \%$ of SLI group mothers had hypertensive disorders compared to $29 \%$ of controls and chorioamnionitis in $13 \%$ of SLI group compared to $10 \%$ of controls.

In this study, there was a statistical difference between groups regarding need to mechanical ventilator, as $34 \%$ of group A and $54 \%$ in group B $(p=0.035)$, there was a statistical difference between groups regarding the time of use of mechanical ventilator, the use of mechanical ventilator in the 1st day was higher $(46 \%)$ in group $\mathrm{B}$, compared to only $14 \%$ of group $\mathrm{A}$, $\mathrm{p}=0.004$; odds ratio $0.439 ; 95 \% \mathrm{CI}(0.196-0.984)$.

This was in agree with [24], Need for MV in the first $72 \mathrm{~h}$ of life was significantly lower in the SLI group when compared with the control group $(25.7 \%$ vs $56.9 \%$, respectively, $\mathrm{P}<0.001)$. Multiple logistic regression analysis showed that SLI (OR: $0.26,95 \%$ CI 0.13 to $0.50 ; \mathrm{P}<0.001$ ). These findings that the strategy of SLI at birth reduces the need for MV within the first $72 \mathrm{~h}$ of life is consistent with and further supports the results of a meta-analysis and several other studies.

On the other side, [15] had a different observations, there was no statistical difference between groups regarding mechanical ventilation at 24 hours of life, 3 patients (15\%) of SLI group and 5 patients $(25 \%) ; \mathrm{p}=0.69$. also [5] had a similar observations

In this study, $34 \%$ of group A required high O2 support compared to $46 \%$ of group B. However, there was no statistical difference between them. Also there was no statistical difference between them regarding the duration of 
high $\mathrm{O} 2$ support or the duration of CPAP, odds ratio $0.605 ; 95 \% \mathrm{CI}(0.270-1.356)$.

Similarly, in [24] study, There were no differences between the SLI and control groups in rates of nIPPV, BiPAP, and nCPAP used as NIV method in NICU $(26.5 \%, 19.5 \%, 46 \%$ vs $24.5 \%$, $12.7 \%, 38.2 \%, \mathrm{P}=0.73, \mathrm{P}=0.18$, and $\mathrm{P}=0.24$, respectively),

In contrast to [25], on a study about the effect of SLI on preterm infants at risk for respiratory distress syndrome, SLI group needed a shorter duration of oxygen therapy $(21 \pm 27$ vs. $31 \pm 31$ days, $\mathrm{p}=0.016)$. Also in [28] study, The use of SLI effectively reduced the oxygen requirement. The mean fraction of inspired oxygen $10 \mathrm{~min}$ after birth was 0.28 (95\% CI, 0.26-0.30) in the SLI group and 0.47 (95\% CI, 0.43-0.52) in the Non-SLI group ( $\mathrm{p}<0.001)$.

In this study, regarding need of survanta, there was no statistical difference between group A and group B (18\% and 22\%, respectively), olds ratio $0.778 ; 95 \%$ CI (0.291-2.082).

Similarly in [6], [24] studies, SLI did not reduce the need for surfactant.

In contrast to [27], SLI group required less surfactant administration than controls (54\% vs $85 \% ; \mathrm{p} \leq 0.001)$

In this study, the overall rate of BPD was $4 \%$ (2 patients) in the group B and 2\% (1 patient) in the group $\mathrm{A}, \mathrm{p}=0.500$, and unadjusted odds ratio was $0.490,95 \% \mathrm{CI}(0.045-5.513)$.

In [23] study, non-significantly different bronchopulmonary dysplasia rates among survivors (2\% in SLI versus $11 \%$ in controls; $\mathrm{p}=0.09$ ). also in a meta-analysis done by [29], sustained inflations had no effect on BPD (RR $0.78,95 \%$ CI $0.57-1.05 ; \mathrm{p}=0.10)$, moreover in [6], the overall rate of BPD was $35 \%$ (50 of 143) in the control group and $38.5 \%$ (57 of 148) in the SLI group.

In contrast to [24], the total incidence of BPD was significantly lower in the SLI group $(31.9 \%$ vs $48 \%, \mathrm{P}=0.01)$; however, moderate and severe $\mathrm{BPD}$ rates did not reached to a statistically significance $(11.5 \%$ vs $20.6 \%, \mathrm{P}=0.06)$

In this study, there was no statistical difference between groups regarding mean length of stay in hospital, was $14.54 \pm 10.2$ in group A and $19.92 \pm 12.6$ in group $\mathrm{B}, \mathrm{p}=0.065$. Also regarding mortality rate $18 \%$ in SLI group and $22 \%$ in controls, $\mathrm{p}=0.402$.

In [15] study, Duration of hospitalization median was 26.5 days (range 15-71) in SLI and 26 days (range 14-116) in controls; $p=0.93$. And in a meta-analysis done by [29], SLI had no effect on death (RR 1.31, 95\% CI 0.80-2.14; p=0.29). moreover many studies observed no statistical relation between SLI maneuver and length of hospital stay and mortality [24], [26]-[28], [30].

\section{Conclusion}

Sustained lung inflation is easier to perform even with a single operator, it reduces the necessity of mechanical ventilator in the first 72 hours without statistically evident adverse effects. However, did not decrease the need for respiratory support, occurrence of BPD, hospitalization or mortality rate.

\section{References}

[1] B. T. Soon, "The Global Action Report on Preterm Birth," Geneva World Heal. Organ., 2012.

[2] S. Safari and M. P. Hamrah, "Epidemiology and related risk factors of preterm labor as an obstetrics emergency," Emergency, VOL...5, 2017.

[3] S. Goedicke-Fritz, C. Härtel, G. KrastevaChrist, M. V Kopp, S. Meyer, and M. Zemlin, "Preterm Birth affects the risk of developing immune-mediated diseases," Front. Immunol., VOL...8, p. 1266, 2017.

[4] S. Reuter, C. Moser, and M. Baack, "Respiratory distress in the newborn," Pediatr. Rev., VOL...35, p. 417, 2014.

[5] D. Mercadante, "Sustained lung inflation in late preterm infants: a randomized controlled trial," J. Perinatol., VOL...36, p. 443, 2016.

[6] G. Lista , "Sustained lung inflation at birth for preterm infants: a randomized clinical trial," Pediatrics, VOL...135, PP. e457-e464, 2015.

[7] M. H. Wyckoff, "Part 13: neonatal resuscitation: 2015 American Heart Association guidelines update for cardiopulmonary resuscitation and emergency cardiovascular care," Circulation, VOL...132, PP. S543-S560, 2015.

[8] J. A. Dawson, A. Gerber, C. O. F. Kamlin, P. G. Davis, and C. J. Morley, "Providing PEEP during neonatal resuscitation: which device is best?," J. Paediatr. Child Health, VOL...47, PP. 698-703, 2011.

[9] S. M. Nimbalkar, S. R. PN, S. V Nesargi, A. R. Dongara, and S. Bhat, "Comparison of efficacy of three devices of manual positive pressure ventilation: a mannequin-based study," Ital. J. Pediatr., VOL...41, p. 25, 2015.

[10]C. C. Roehr, M. Kelm, H. S. Fischer, C. Bührer, G. Schmalisch, and H. Proquitté, "Manual ventilation devices in neonatal resuscitation: tidal Vol..ume and positive pressure-provision," Resuscitation, VOL...81, PP. 202-205, 2010.

[11]A. B. te Pas and F. J. Walther, "A randomized, controlled trial of delivery-room respiratory management in very preterm infants," Pediatrics, VOL...120, PP. 322-329, 2007. 
[12]A. B. Te Pas , "Establishing functional residual capacity at birth: the effect of sustained inflation and positive endexpiratory pressure in a preterm rabbit model," Pediatr. Res., VOL...65, p. 537, 2009.

[13] J. M. Perlman, "Neonatal Resuscitation Chapter Collaborators. Neonatal Resuscitation: 2010 International Consensus on Cardiopulmonary Resuscitation and Emergency Cardiovascular Care Science With Treatment Recommendations Part 11," Circulation, VOL...122, PP. S516-S538, 2010.

[14] M. P. T. Simplício, A. Q. Ribeiro, L. F. R. Sant'Ana, J. F. de Novaes, S. E. Priore, and S. do C. C. Franceschini, "Growth curves and dietary profile of preterm newborns with appropriate weight for gestational age during hospital stay," Rev. Paul. Pediatr., VOL...30, PP. 359-368, 2012.

[15]B. Schwaberger, G. Pichler, A. Avian, C. Binder-Heschl, N. Baik, and B. Urlesberger, "Do sustained lung inflations during neonatal resuscitation affect cerebral blood Vol..ume in preterm infants? A randomized controlled pilot study," PLoS One, VOL... 10, p. e0138964, 2015.

[16] S.-Y. Shim, S. J. Cho, K. A. Kong, and E. A. Park, "Gestational age-specific sex difference in mortality and morbidities of preterm infants: A nationwide study," Sci. Rep., VOL...7, p. 6161, 2017.

[17] A. L. Kent, I. M. R. Wright, and M. E. Abdel-Latif, "Mortality and adverse neurologic outcomes are greater in preterm male infants," Pediatrics, VOL...129, PP. 124-131, 2012.

[18] J. A. McGregor, M. Leff, M. Orleans, and A. Baron, "Fetal gender differences in preterm birth: findings in a North American cohort," Am. J. Perinatol., VOL...9, PP. 43-48, 1992.

[19] J. Zeitlin , "Fetal sex and preterm birth: are males at greater risk?," Hum. Reprod., VOL...17, PP. 2762-2768, 2002.

[20] D. N. O'Driscoll, M. McGovern, C. M. Greene, and E. J. Molloy, "Gender disparities in preterm neonatal outcomes," Acta Paediatr, VOL...107, PP. 1494-1499, 2018.

[21] J. J. van Vonderen, S. B. Hooper, H. D. Hummler, E. Lopriore, and A. B. te Pas, "Effects of a sustained inflation in preterm infants at birth,” J Pediatr, VOL...165, 2014.
[22] S. R. Murray, S. J. Stock, S. Cowan, E. S. Cooper, and J. E. Norman, "Spontaneous preterm birth prevention in multiple pregnancy," Obstet. Gynaecol., VOL...20, p. 57, 2018.

[23]M. S. El-Chimi, H. A. Awad, T. M. ElGammasy, O. G. El-Farghali, M. T. Sallam, and D. M. Shinkar, "Sustained versus intermittent lung inflation for resuscitation of preterm infants: a randomized controlled trial," J. Matern. Neonatal Med., VOL...30, PP. 1273-1278, 2017.

[24] M. Buyuktiryaki, "Sustained lung inflation at birth via short binasal prong in very low birth weight preterm infants: A retrospective study," Pediatr. Pulmonol., VOL...53, PP. 1407-1413, 2018.

[25] G. Lista, P. Fontana, F. Castoldi, F. Cavigioli, and C. Dani, "Does sustained lung inflation at birth improve outcome of preterm infants at risk for respiratory distress syndrome?," Neonatology, VOL...99, PP. 45-50, 2011.

[26] G. M. Schmölzer, M. Kumar, K. Aziz, G. Pichler, M. O'Reilly, and G. Lista, "Sustained inflation versus positive pressure ventilation at birth: a systematic review and meta-analysis," Arch Dis Child Fetal Neonatal Ed, VOL...100, 2015.

[27]C. Grasso ,"Effects of Sustained Lung Inflation, a lung recruitment maneuver in primary acute respiratory distress syndrome, in respiratory and cerebral outcomes in preterm infants," Early Hum. Dev., VOL...91, PP. 71-75, 2015.

[28]P. Jiravisitkul, S. Rattanasiri, and P. Nuntnarumit, "Randomised controlled trial of sustained lung inflation for resuscitation of preterm infants in the delivery room," Resuscitation, VOL...111, PP. 68-73, 2017.

[29]H. S. Fischer, G. M. Schmölzer, P.-Y. Cheung, and C. Buehrer, "Sustained inflations and avoiding mechanical ventilation to prevent death or bronchopulmonary dysplasia: a metaanalysis," Eur. Respir. Rev., VOL...27, p. 180083, 2018.

[30] G. R. Polglase, D. G. Tingay, R. Bhatia, C. A. Berry, R. J. Kopotic, and C. P. Kopotic, "Pressure-versus Vol..ume-limited sustained inflations at resuscitation of premature newborn lambs," BMC Pediatr, VOL...14, 2014. 